\title{
Implications of anthropogenic landscape change on inter-population movements of the desert tortoise (Gopherus agassizii)
}

\author{
Taylor Edwards ${ }^{1, *}$, Cecil R. Schwalbe ${ }^{1,2}$, Don E. Swann ${ }^{3}$ \& Caren S. Goldberg ${ }^{1}$ \\ ${ }^{1}$ School of Natural Resources, University of Arizona, 125 Biological Sciences East, Tucson, AZ 85721, USA; \\ ${ }^{2}$ U.S. Geological Survey, Southwest Biological Science Center, University of Arizona, Tucson, AZ 85721, \\ USA; ${ }^{3}$ National Park Service, Saguaro National Park, Tucson, AZ 85730, USA (*Author for correspon- \\ dence: fax: +1-520-670-5001; e-mail: tayache@ag.arizona.edu)
}

Received 12 June 2003; accepted 6 January 2004

Key words: conservation, desert tortoise, gene flow, Gopherus agassizii, microsatellite

\begin{abstract}
In the Sonoran Desert of North America, populations of the desert tortoise (Gopherus agassizii) occur in rocky foothills throughout southwestern Arizona and northwestern Mexico. Although tortoise populations appear to be isolated from each other by low desert valleys, individuals occasionally move long distances between populations. Increasingly, these movements are hindered by habitat fragmentation due to anthropogenic landscape changes. We used molecular techniques and radiotelemetry to examine movement patterns of desert tortoises in southern Arizona. We collected blood samples from 170 individuals in nine mountain ranges and analyzed variability in seven microsatellite loci to determine genetic differentiation among populations. Gene flow estimates between populations indicate that populations exchanged individuals historically at a rate greater than one migrant per generation, and positive correlation between genetic and geographic distance of population pairs suggests that the limiting factor for gene flow among populations is isolation by distance. Life history traits of the desert tortoise, a long-lived species with delayed sexual maturity, may severely constrain the ability of small populations to respond to disturbances that increase adult mortality. Historic gene flow estimates among populations suggests that recovery of declining populations may rely heavily on the immigration of new individuals from adjacent mountain ranges. Management strategies compatible with the evolutionary history of gene flow among disjunct populations will help ensure the long-term persistence of Sonoran desert tortoise populations.
\end{abstract}

\section{Introduction}

The desert tortoise, Gopherus agassizii, is native to the southwestern deserts of North America and is recognized as having distinct Mojave and Sonoran populations. The Mojave population (defined as all tortoises north and west of the Colorado River) was federally listed as threatened by the US Fish and Wildlife Service in 1990 (USFWS 1990). The Sonoran population (all tortoises south and east of the Colorado River) is not federally listed but is considered a Species of Special Concern by the Arizona Game and Fish Department (AGFD 1996). Although a number of threats to tortoises have been identified, loss of habitat currently represents the greatest threat to Sonoran populations near rapidly growing communities such as Phoenix and Tucson (Figure 1; AIDTT 2000). In the Tucson area, many thousands of acres of tortoise habitat have been recently lost to large residential developments in the foothills of the Santa Catalina, Tortolita, Rincon, and Tucson Mountains. Development reduces the size of populations and isolates them by creating barriers such as highways and canals. There is a strong management need to identify important connections between tortoise populations before the opportunity to preserve these connections is gone (AIDTT 1996). 


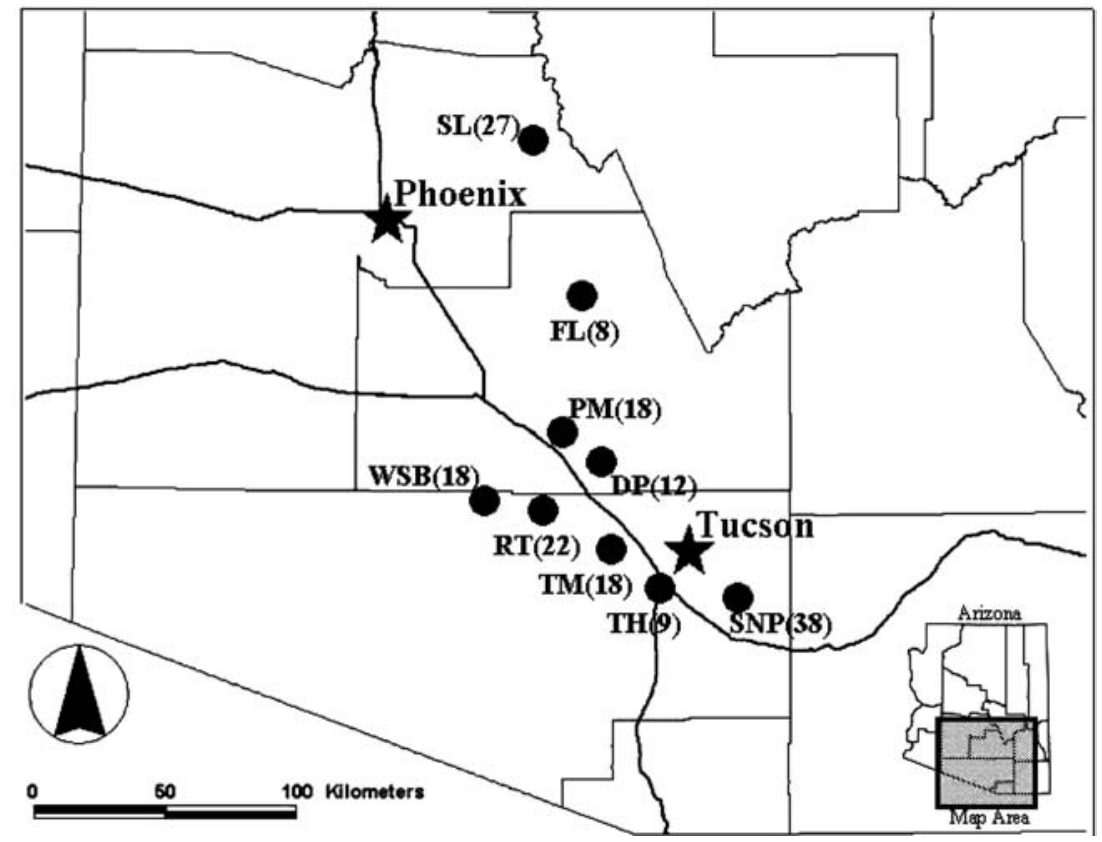

Figure 1. Location and number of tortoises sampled from nine mountain ranges containing desert tortoise populations in southern Arizona; Desert Peak (DP), Florence Military Reservation (FL), Picacho Mountains (PM), Ragged Top (RT), Rincon Mountains (Rincon Mountain District of Saguaro National Park; SNP), Sugarloaf (SL), Tumamoc Hill (TH), Tucson Mountains (TM), and West Silver Bell Mountains (WSB).

Tortoises in southern Arizona generally inhabit rocky foothills associated with leguminous trees (foothill paloverde, Parkinsonia microphylla; desert ironwood, Olneya tesota) and mixed cacti (saguaro cactus, Carnegiea gigantea; cholla, Opuntia spp.) characteristic of Arizona Upland Sonoran desertscrub (Turner and Brown 1982). Although foothill populations appear to be isolated by low desert valleys, radiotelemetry data show that tortoises are capable of making long-distance movements between populations (Barrett et al. 1990; Averill-Murray and Klug 2000; Edwards 2003). However, the importance of these movements and whether they contribute to gene flow is unknown. Determination of the extent to which disjunct populations interact is an important aspect of desert tortoise conservation.

We used seven microsatellite DNA markers to examine the genetic relationships of tortoises in eight populations in the vicinity of Tucson and one population northeast of Phoenix. By comparing genetic distance (variation between populations) with geographic distance and calculating migration rates among these populations, we estimated historic rates of gene flow. We then used GIS data to denote human barriers that potentially obstruct tortoise movements. In addition, we evaluated genetic relatedness among individual desert tortoises within a single population located in the Rincon Mountain District of Saguaro National Park while simultaneously gathering information on movements and home ranges using radiotelemetry. For this population, we compared genetic differences among individuals to geographic distances between them to determine if gene flow within the population is random in regard to geographical location of individuals or if habitat features such as ridges and drainages influence population structure.

Because major human development is fairly recent (Lovich and Bainbridge 1999) with respect to the generation time of the desert tortoise (estimated at 25 years; USFWS 1994), the genetic structure of tortoise populations has not likely been affected by modern anthropogenic landscape changes yet. By measuring gene flow among populations, we can obtain a snapshot of the movement patterns of desert tortoises prior to anthropogenic habitat fragmentation. The degree of relatedness of tortoises both within and among mountain ranges has implications for how sustainable small populations may be as they become increasingly isolated. 


\section{Methods}

\section{Data collection}

We sampled desert tortoises in Arizona from eight sites in the vicinity of Tucson and from one population northeast of Phoenix (Figure 1). The maximum distance between any two populations was $186 \mathrm{~km}$, the minimum distance $16 \mathrm{~km}$. Between 8 and 38 tortoises were sampled from each population, depending on population size, for a total of 170 tortoises. We hand-captured and processed tortoises March-October 2000 and 2001 using standard methods and following Arizona Interagency Desert Tortoise Team guidelines (Averill-Murray 2000). We collected <3 cc blood by brachial or jugular venipuncture and stored it on ice with an EDTA or lithium heparin buffer.

\section{Molecular techniques}

We isolated total DNA from blood by overnight lysis with proteinase $\mathrm{K}$ at $55^{\circ} \mathrm{C}$, followed by a phenol/chloroform extraction and isopropanol/ sodium acetate precipitation (Goldberg et al. 2003). The EDTA and lithium heparin buffers we used for tissue storage did not affect our yield using this extraction protocol. We resuspended the DNA in low TE (10 mM Tris-pH 8.0, $0.1 \mathrm{mM}$ EDTA) and diluted to a $5 \mathrm{ng} / \mu \mathrm{l}$ working stock for polymerase chain reaction (PCR) amplifications. We prepared a microsatellite-enriched genomic library for tortoises based on the methods of Hamilton et al. (1999) and identified six novel microsatellite loci that exhibited variation in our sample set. Three loci, Goag3, Goag4, and Goag5 consisted of tri-nucleotide repeat motifs and the others, Goag6, Goag7, and Goag32 were di-nucleotides. (GenBank accession numbers; AY317141AY317145 and AY317147). We PCR-amplified these six loci and assessed variability using $5^{\prime}$ fluorescently labeled forward primers as described in Edwards et al. (2003). In addition, we tested 11 microsatellite loci identified in several other chelonian species: Chelonia mydas (Cm3, Cm58, Cm72, Cm84), Caretta caretta (Cc117, Cc7), Eretmochelys imbricata (Ei8) and Podocnemis expansa (PE334, PE519, PE107) (FitzSimmons et al. 1995, FitzSimmons 1998, Sites et al. 1999). Cm58 was variable in our desert tortoise sample set and was used in our analyses.
Analysis

We calculated microsatellite allele frequencies for each locus in each population and we examined frequency distributions for unique and private alleles. We compared allele frequency distributions between all population pairs and between each population and the total sample for all loci exhibiting greater than seven alleles using a Kolmogorov-Smirnov test (KS-test; Chakravarti et al. 1967). The KS-test is a non-parametric test that determines if two datasets differ significantly without making assumptions about the distribution of data. We choose the KS-test over the loglikelihood (G) based exact test (Goudet et al. 1996) offered in GENEPOP (Raymond and Rousset 1995) because the G-test is sensitive to unbalanced sampling distributions, as was the case with our data. We used ARLEQUIN (version 2.0, Schneider et al. 2000) to detect significant departure from Hardy-Weinberg equilibrium at each locus using a triangular contingency table and a modified version of the Markov-chain random walk algorithm (Guo and Thompson 1992). We tested for linkage disequilibrium (nonrandom association between loci) among all pairs of loci in the entire sample and within each population using a likelihood-ratio test with an empirical distribution obtained by permutation (Slatkin and Excoffier 1996). We used default parameters in ARLEQUIN for all Markov-chain tests and permutations. We determined the inbreeding coefficient $\left(F_{\text {IS }}\right.$; Weir \& Cockerham 1984) for each locus in each population using GENEPOP version 3.1 (Raymond and Rousset 1995).

We used BOTTLENECK (Piry et al. 1999) to identify recent bottlenecks in each population and in the entire sample. This test is based on the assumption that a bottlenecked population (one that has experienced recent reductions in effective population size) will show an excess of heterozygosity over that expected under mutation-drift equilibrium (Cornuet and Luikart 1996). In addition, we used the method of Garza and Williamson (2001) to assess recent reductions in population size. This method examines the ratio of the total number of alleles to the overall range in allele size $(M)$. $M$ can be interpreted as the average percentage of intermediate allelic states in a population and its value will decrease when a population is reduced in size. We calculated $M$ for each 
population and for the total region and then simulated $M$ (10,000 replicates) based on the allelic frequencies of the sample populations using three parameters: theta $\left(4 \mathrm{~N}_{\mathrm{e}} \mu\right), P_{\mathrm{S}}$ (percentage of mutations that add or delete only one repeat), and delta $_{\mathrm{g}}$ (mean size of larger mutations). Simulations generated a statistic $M_{\mathrm{C}}$, which is the critical value at which $95 \%$ of the simulations of $M$ in an equilibrium population are greater than $M_{\mathrm{C}}$. A reduction in population size is suggested when $M<M_{\mathrm{C}}$. We used two models; one recommended by Garza and Williamson $\left(\theta=10, P_{\mathrm{S}}=0.9\right.$ and $\delta_{\mathrm{g}}=3.5$ ) and a more conservative model based on microsatellite data sets from 20 natural populations (Garza and Williamson 2001; $\theta=10$, $P_{\mathrm{S}}=0.88$ and $\left.\delta_{\mathrm{g}}=2.8\right)$. A $\theta$ value of 10 represents an effective population size of 5000 individuals (with mutation rate $\mu=5 \times 10^{-4}$ ). This value is a compromise between underestimating the population size of the entire region, and overestimating the population size in each mountain range.

We tested population assignment of individuals using WHICHRUN (version 4.1; Banks and Eichert 2000). WHICHRUN uses jackknife iterations to evaluate the chances of correct allocation for each individual in the sample. Stringency for population allocation is resolved by defining a selection criterion for the log of the odds ratio (LOD) for the two most likely source populations. Assignments that have a LOD ratio of at least 2 will have a $1 / 100$ chance of error or less. We inferred population structure from microsatellite data using AMOVA (analysis of molecular variance) in ARLEQUIN. We used $\Phi_{\mathrm{ST}}$ (Weir and Cockerham 1984) to determine how genetic variation was partitioned within the region, among populations, and among individuals within populations. We used FSTAT version 2.9.3.2 (Goudet $1995)$ to calculate bootstrap estimators for significance of $F$-statistics. As a comparison, we also calculated genetic variability using a stepwise mutation model, Slatkin's $R_{\mathrm{ST}}$ (Slatkin 1995), in ARLEQUIN. We calculated genetic distances among populations and individuals using ARLEQUIN based on pairwise $\Phi_{\mathrm{ST}}$. Negative $\Phi_{\mathrm{ST}}$ and $R_{\mathrm{ST}}$ values were treated as zero. We estimated the number of migrants exchanged per generation between pairs of populations $(2 \mathrm{Nm})$ using Slatkin's $\widehat{M}$ (Slatkin 1991) in ARLEQUIN as well as using the private allele method of Barton and Slatkin (1986) in GENEPOP. We used NTSYSpc (version 2.02h, Applied Biostatistics Inc.) to perform mantel tests to assess correlation between genetic distances $\left(\Phi_{\mathrm{ST}}\right)$ and geographic distances among populations. If gene flow has been the determinant of genetic structure among populations and geographic distance between populations affects the dispersal of individuals between populations, then the correlation between the matrices should be significant (Slatkin and Maddison 1990).

\section{Radiotelemetry and spatial analysis}

We assessed within-population genetic structure at two established study sites in the Rincon Mountain District of Saguaro National Park. The first site (Mother's Day Fire) lies entirely within the park boundary. We have radiotracked nine tortoises here since 1996 (Esque et al. 1998). The second site (Rocking $\mathrm{K}$ ) is approximately six $\mathrm{km}$ south of the Mother's Day Fire and is located along the park's south boundary. We have radiotracked 25 tortoises at this site since July 1999. We monitored tortoises, on average, twice weekly during the active season (March-October) and once weekly during winter. We collected blood samples from all radiotelemetered tortoises at these sites for genetic analysis.

We mapped potential human-constructed barriers to tortoise movement between mountain ranges in ArcView GIS (version 3.2, Environmental Systems Research Institute, Inc.) based on available GIS data. We used straight-line distance as a measure of geographic distance between populations because evidence suggests that longdistance movements of tortoises and other reptiles do not follow natural geographic forms but are essentially linear in nature (Barrett et al. 1990; King and Duvall 1990; Reinert and Rupert 1999). Within the Saguaro National Park radiotelemetry plots, we located tortoises to within approximately five meters using hand-held Global Positioning System (GPS) receivers (GARMIN International Inc.). We determined the arithmetic mean of all point locations for each individual from all years for which telemetry data were available using the Animal Movement Analyst Extension (version 1.1, Hooge and Eichenlaub 1997) in ArcView and used that point location to determine the geographic distances among the 34 individual tortoise home ranges. We used NTSYSpc to perform Mantel 
tests to assess correlation between genetic distances $\left(\Phi_{\mathrm{ST}}\right)$ and geographic distances among individual tortoises. We determined the most likely site of origin for each individual in the population using the population assignment test in WHICHRUN. We used available base coverages from digital orthophoto quarter quads (DOQQs) to assess presence of physical features such as ridges and drainages between plots.

\section{Results}

\section{Microsatellite DNA results}

In our trial of 11 microsatellite loci from other chelonian species, we successfully amplified two loci in the desert tortoise genome ( $\mathrm{Cm} 58$ and $\mathrm{Cc} 7)$. Interestingly, the repeat array for both loci were dramatically different in the desert tortoise; for $\mathrm{Cm} 58,(\mathrm{CA})_{2} \mathrm{CG}(\mathrm{CT})_{4}$ instead of $(\mathrm{CA})_{13}$, and for $\mathrm{Cc} 7,(\mathrm{CA})_{5}(\mathrm{TC})_{4}(\mathrm{CA})_{2}$ instead of $(\mathrm{CA})_{14}$. We confirmed that these were in fact the same loci by comparing flanking sequences from each species. In a test of eight samples representing eight populations, Cc7 proved monomorphic in our sample of desert tortoises. $\mathrm{Cm} 58$ expressed two alleles in our sample set and was used in our analyses.

A total of seven microsatellite loci were amplified and sized for all 170 samples from nine populations (Table 1). All seven loci were polymorphic in all populations. Loci Goag3, Goag32, and $\mathrm{Cm} 58$ exhibited only marginal variability (2-3 alleles), but loci Goag4, Goag5, Goag6, and Goag7 were highly variable (8-27 alleles). The allelic distributions for these loci did not exhibit normality. The KS-test found less than $5 \%$ of the population pairwise comparisons between distributions of allelic frequencies for the more variable loci (Goag4, Goag5, Goag6, and Goag7) to be significantly different. Where there were significant differences in the allelic distributions between two populations, there was not a consistent pattern in a specific population, between a specific population pair, or at a specific locus. Unique alleles were detected in the six populations with the largest sample sizes (Table 2). Only four private alleles (frequency $\geq 5 \%$ ) were detected, one in each of four populations. No private alleles had frequencies greater than $7 \%$ in a population. The mean frequency of private alleles $[P(1)]$ for our total sample was 0.034 .
Three of our loci (Goag5, Goag6, and Goag7) deviated significantly from expected heterozygosities under Hardy-Weinberg proportions over all populations using exact probability testing (Edwards et al. 2003) and the associated inbreeding estimator $\left(\Phi_{\mathrm{IS}}\right)$ at these three loci was positive. $\Phi_{\text {IS }}$ over all loci for the entire sample was 0.161 (99\% confidence interval for bootstrapping across loci: 0.016-0.376). Tests for linkage disequilibrium rejected the null hypothesis of independence of four of our seven loci (Goag4 linked to Goag5 and Goag7; Goag7 linked to Goag32). However, analyses performed without any combination of three of the linked loci did not affect the results of the AMOVA or the genetic distance calculations. We proceeded with analysis using the full set of loci, but also calculated descriptive statistics with the exclusion of the apparently linked loci for comparison.

We did not find significant excess or deficiency in heterozygosity per population when all loci in the sample set were examined together. The entire sample and each individual population fit the expected beta distribution, suggesting that there have not been recent reductions in population size (Cornuet and Luikart 1996). Using the method of Garza and Williamson (2001), all values generated for the average percentage of intermediate allelic states $(M)$ for both models fell above the critical value $M_{\mathrm{C}}$.

\section{Population Differentiation}

Less than $30 \%$ of individuals were allocated to their correct population using WHICHRUN, and of those only one had a LOD of greater than two when compared to the next most likely population assignment. Hierarchical analysis of molecular variance of microsatellite data detected only minimal genetic differences between pairs of desert tortoise populations from adjacent mountain ranges (Table 3). For non-adjacent pairs, genetic distance was correlated with geographic distance. The AMOVA revealed that $96.3 \%(P<0.001)$ of the observed diversity was in individuals within populations $\left(\Phi_{\mathrm{IT}}=0.963\right)$, while only $3.7 \%$ $(P<0.001)$ of the variation was among populations $\left(\Phi_{\mathrm{ST}}=0.037 ; 99 \%\right.$ confidence interval for bootstrapping across loci: 0.017-0.053). Estimates using a stepwise mutation model also showed very weak differentiation among populations, with 
Table 1. Diversity indices for seven microsatellite loci in nine populations of desert tortoises

\begin{tabular}{|c|c|c|c|c|c|c|c|c|}
\hline Population & $\#$ & Size & $\mathrm{H}_{\mathrm{obs}}$ & $H_{\exp }$ & $P$ & SD & $F_{\mathrm{IS}}$ & $P$ \\
\hline \multicolumn{9}{|l|}{ Goag3 } \\
\hline Desert Peak & 12 & $6-8$ & 0.333 & 0.370 & 1.000 & $<0.001$ & -0.114 & 1.000 \\
\hline Florence & 8 & $6-8$ & 0.625 & 0.575 & 1.000 & $<0.001$ & -0.296 & 1.000 \\
\hline Rincon Mountains (SNP) & 38 & $6-8$ & 0.436 & 0.461 & 0.761 & 0.004 & 0.056 & 0.757 \\
\hline Picacho Mountains & 18 & $6-8$ & 0.333 & 0.459 & 0.272 & 0.004 & 0.206 & 0.260 \\
\hline Ragged Top & 22 & $6-8$ & 0.318 & 0.354 & 0.376 & 0.004 & 0.104 & 0.384 \\
\hline Sugarloaf & 27 & $6-8$ & 0.296 & 0.300 & 1.000 & $<0.001$ & -0.106 & 1.000 \\
\hline Tumamoc Hill & 9 & $6-8$ & 0.333 & 0.294 & 1.000 & $<0.001$ & -0.143 & 1.000 \\
\hline Tucson Mountains & 18 & $6-8$ & 0.556 & 0.452 & 0.771 & 0.004 & -0.236 & 0.755 \\
\hline West Silver Bell Mountains & 18 & $6-8$ & 0.111 & 0.162 & 1.000 & $<0.001$ & -0.015 & 1.000 \\
\hline Across all populations & 170 & $6-8$ & 0.363 & 0.364 & 0.695 & 0.005 & -0.008 & 0.666 \\
\hline \multicolumn{9}{|l|}{ Goag4 } \\
\hline Desert Peak & 12 & $10-23$ & 0.250 & 0.235 & 1.000 & $<0.001$ & -0.065 & 1.000 \\
\hline Florence & 8 & $10-15$ & 0.625 & 0.458 & 0.487 & 0.005 & -0.400 & 0.487 \\
\hline Rincon Mountains (SNP) & 38 & $9-25$ & 0.769 & 0.754 & 0.858 & 0.003 & -0.020 & 0.861 \\
\hline Picacho Mountains & 18 & $9-29$ & 0.778 & 0.732 & 0.543 & 0.002 & -0.065 & 0.558 \\
\hline Ragged Top & 22 & $9-25$ & 0.682 & 0.760 & 0.790 & 0.002 & 0.082 & 0.750 \\
\hline Sugarloaf & 27 & $9-24$ & 0.519 & 0.565 & 0.616 & 0.003 & 0.033 & 0.542 \\
\hline Tumamoc Hill & 9 & $9-23$ & 0.778 & 0.771 & 0.739 & 0.002 & -0.009 & 0.702 \\
\hline Tucson Mountains & 18 & $9-23$ & 0.444 & 0.435 & 0.526 & 0.003 & -0.023 & 0.571 \\
\hline West Silver Bell Mountains & 18 & $7-24$ & 0.722 & 0.779 & 0.308 & 0.001 & 0.043 & 0.225 \\
\hline Across all populations & 170 & $7-29$ & 0.637 & 0.662 & 0.510 & 0.002 & 0.037 & 0.094 \\
\hline \multicolumn{9}{|l|}{ Goag 5} \\
\hline Desert Peak & 12 & $9-34$ & 1.000 & 0.935 & 0.894 & 0.001 & -0.073 & 0.739 \\
\hline Florence & 8 & $14-29$ & 0.750 & 0.850 & 0.391 & 0.002 & 0.097 & 0.407 \\
\hline Rincon Mountains (SNP) & 38 & $9-38$ & 0.820 & 0.926 & 0.036 & $<0.001$ & 0.115 & 0.001 \\
\hline Picacho Mountains & 18 & $6-34$ & 1.000 & 0.922 & 0.034 & $<0.001$ & -0.087 & 0.014 \\
\hline Ragged Top & 22 & $9-35$ & 0.909 & 0.935 & 0.761 & 0.001 & 0.028 & 0.909 \\
\hline Sugarloaf & 27 & $9-27$ & 0.889 & 0.859 & 0.068 & 0.001 & -0.035 & 0.072 \\
\hline Tumamoc Hill & 9 & $9-32$ & 1.000 & 0.882 & 0.433 & 0.001 & -0.143 & 0.422 \\
\hline Tucson Mountains & 18 & $15-38$ & 0.889 & 0.911 & 0.040 & 0.001 & 0.016 & 0.174 \\
\hline West Silver Bell Mountains & 18 & $12-33$ & 0.778 & 0.927 & 0.024 & 0.001 & 0.165 & 0.043 \\
\hline Across all populations & 170 & $6-38$ & 0.883 & 0.921 & $<0.001$ & $<0.001$ & 0.041 & 0.021 \\
\hline \multicolumn{9}{|l|}{ Goag6 } \\
\hline Desert Peak & 12 & $15-27$ & 0.083 & 0.649 & $<0.001$ & $<0.001$ & 0.863 & $<0.001$ \\
\hline Florence & 8 & $15-25$ & 0.375 & 0.825 & 0.130 & 0.004 & 0.506 & 0.115 \\
\hline Rincon Mountains (SNP) & 38 & $15-26$ & 0.154 & 0.694 & $<0.001$ & $<0.001$ & 0.773 & $<0.001$ \\
\hline Picacho Mountains & 18 & $15-29$ & 0.444 & 0.681 & 0.066 & 0.001 & 0.322 & 0.079 \\
\hline Ragged Top & 22 & $15-51$ & 0.500 & 0.748 & 0.006 & 0.001 & 0.335 & 0.002 \\
\hline Sugarloaf & 27 & $17-49$ & 0.444 & 0.722 & $<0.001$ & $<0.001$ & 0.365 & 0.001 \\
\hline Tumamoc Hill & 9 & $15-25$ & 0.333 & 0.686 & 0.086 & 0.002 & 0.455 & 0.071 \\
\hline Tucson Mountains & 18 & $15-25$ & 0.333 & 0.683 & $<0.001$ & $<0.001$ & 0.485 & $<0.001$ \\
\hline West Silver Bell Mountains & 18 & $15-52$ & 0.389 & 0.676 & $<0.001$ & $<0.001$ & 0.402 & 0.001 \\
\hline Across all populations & 170 & $15-52$ & 0.333 & 0.697 & $<0.001$ & $<0.001$ & 0.519 & $<0.001$ \\
\hline
\end{tabular}


Table 1. (Continued)

\begin{tabular}{|c|c|c|c|c|c|c|c|c|}
\hline Population & $\#$ & Size & $\mathrm{H}_{\mathrm{obs}}$ & $H_{\exp }$ & $P$ & SD & $F_{\text {IS }}$ & $P$ \\
\hline \multicolumn{9}{|l|}{ Goag7 } \\
\hline Desert Peak & 12 & $12-18$ & 0.333 & 0.598 & 0.038 & 0.002 & 0.385 & 0.029 \\
\hline Florence & 8 & $14-22$ & 0.500 & 0.733 & 0.241 & 0.009 & 0.253 & 0.262 \\
\hline Rincon Mountains (SNP) & 38 & $12-22$ & 0.385 & 0.620 & $<0.001$ & $<0.001$ & 0.376 & 0.002 \\
\hline Picacho Mountains & 18 & $12-22$ & 0.611 & 0.670 & 0.753 & 0.003 & 0.043 & 0.742 \\
\hline Ragged Top & 22 & $12-19$ & 0.500 & 0.587 & 0.378 & 0.004 & 0.151 & 0.326 \\
\hline Sugarloaf & 27 & $14-22$ & 0.667 & 0.751 & 0.206 & 0.004 & 0.097 & 0.200 \\
\hline Tumamoc Hill & 9 & $12-18$ & 0.222 & 0.471 & 0.366 & 0.004 & 0.439 & 0.341 \\
\hline Tucson Mountains & 18 & $12-22$ & 0.500 & 0.605 & 0.332 & 0.002 & 0.126 & 0.339 \\
\hline West Silver Bell Mountains & 18 & $12-21$ & 0.389 & 0.754 & $<0.001$ & $<0.001$ & 0.466 & 0.001 \\
\hline Across all populations & 170 & $12-22$ & 0.474 & 0.669 & $<0.001$ & $<0.001$ & 0.288 & $<0.001$ \\
\hline \multicolumn{9}{|l|}{ Goag32 } \\
\hline Desert Peak & 12 & $5-6$ & 0.250 & 0.301 & 1.000 & $<0.001$ & -0.100 & 1.000 \\
\hline Florence & 8 & $5-6$ & 0.125 & 0.242 & 1.000 & $<0.001$ & 0.000 & - \\
\hline Rincon Mountains (SNP) & 38 & $5-6$ & 0.205 & 0.249 & 0.493 & 0.005 & 0.095 & 0.483 \\
\hline Picacho Mountains & 18 & $5-6$ & 0.111 & 0.203 & 0.177 & 0.005 & 0.460 & 0.169 \\
\hline Ragged Top & 22 & $5-6$ & 0.409 & 0.458 & 1.000 & $<0.001$ & 0.041 & 1.000 \\
\hline Sugarloaf & 27 & $5-6$ & 0.481 & 0.400 & 0.288 & 0.005 & -0.300 & 0.283 \\
\hline Tumamoc Hill & 9 & $5-6$ & 0.222 & 0.307 & 1.000 & $<0.001$ & -0.067 & 1.000 \\
\hline Tucson Mountains & 18 & $5-6$ & 0.500 & 0.437 & 1.000 & $<0.001$ & -0.150 & 1.000 \\
\hline West Silver Bell Mountains & 18 & $5-6$ & 0.167 & 0.208 & 1.000 & $<0.001$ & -0.062 & 1.000 \\
\hline Across all populations & 170 & $5-6$ & 0.292 & 0.295 & 1.000 & $<0.001$ & -0.008 & 1.000 \\
\hline \multicolumn{9}{|l|}{$\mathrm{Cm} 58$} \\
\hline Desert Peak & 12 & $7-8$ & 0.333 & 0.359 & 1.000 & $<0.001$ & -0.158 & 1.000 \\
\hline Florence & 8 & $7-8$ & 0.375 & 0.592 & 0.539 & 0.005 & 0.300 & 0.530 \\
\hline Rincon Mountains (SNP) & 38 & $7-8$ & 0.333 & 0.335 & 1.000 & $<0.001$ & -0.060 & 1.000 \\
\hline Picacho Mountains & 18 & $7-8$ & 0.167 & 0.367 & 0.085 & 0.002 & 0.490 & 0.085 \\
\hline Ragged Top & 22 & $7-8$ & 0.318 & 0.274 & 1.000 & $<0.001$ & -0.167 & 1.000 \\
\hline Sugarloaf & 27 & $7-8$ & 0.333 & 0.360 & 1.000 & $<0.001$ & -0.009 & 1.000 \\
\hline Tumamoc Hill & 9 & $7-8$ & 0.111 & 0.216 & 1.000 & $<0.001$ & 0.000 & - \\
\hline Tucson Mountains & 18 & $7-8$ & 0.167 & 0.157 & 1.000 & $<0.001$ & -0.062 & 1.000 \\
\hline West Silver Bell Mountains & 18 & $7-8$ & 0.167 & 0.208 & 1.000 & $<0.001$ & -0.062 & 1.000 \\
\hline Across all populations & 170 & $7-8$ & 0.269 & 0.287 & 0.602 & 0.0048 & 0.048 & 0.585 \\
\hline
\end{tabular}

\# - number of individuals genotyped; Size - the range of allele repeat lengths; $H_{\mathrm{obs}}-$ observed heterozygosity; $H_{\mathrm{exp}}$ - expected heterozygosity; $\mathrm{SD}$ - standard deviation of randomization tests for Hardy-Weinberg equilibrium; and $F_{\mathrm{IS}}$ - Weir and Cockerham's inbreeding estimator (1984) (Edwards et al. 2003).

96.8\% $(P<0.004)$ of genetic variation in individuals within populations $\left(R_{\mathrm{IT}}\right)$ and $3.2 \%$ $(P<0.001)$ of variation among populations $\left(R_{\mathrm{ST}}\right) . F$-coefficients calculated with the exclusion of the potentially linked loci did not differ sufficiently to change the interpretation of the data. Estimates of the number of migrants per generation between populations using Slatkin's $\widehat{M}$
(Table 4) ranged from 2.9 (Tumamoc Hill/Florence) to "infinite" (Ragged Top/Picacho Mountains). The estimate for effective number of migrants (corrected for population size) between populations using the private alleles method was 5.5 per generation.

There was a significant, positive correlation between genetic distance (pairwise $\Phi_{\mathrm{ST}}$ ) and 


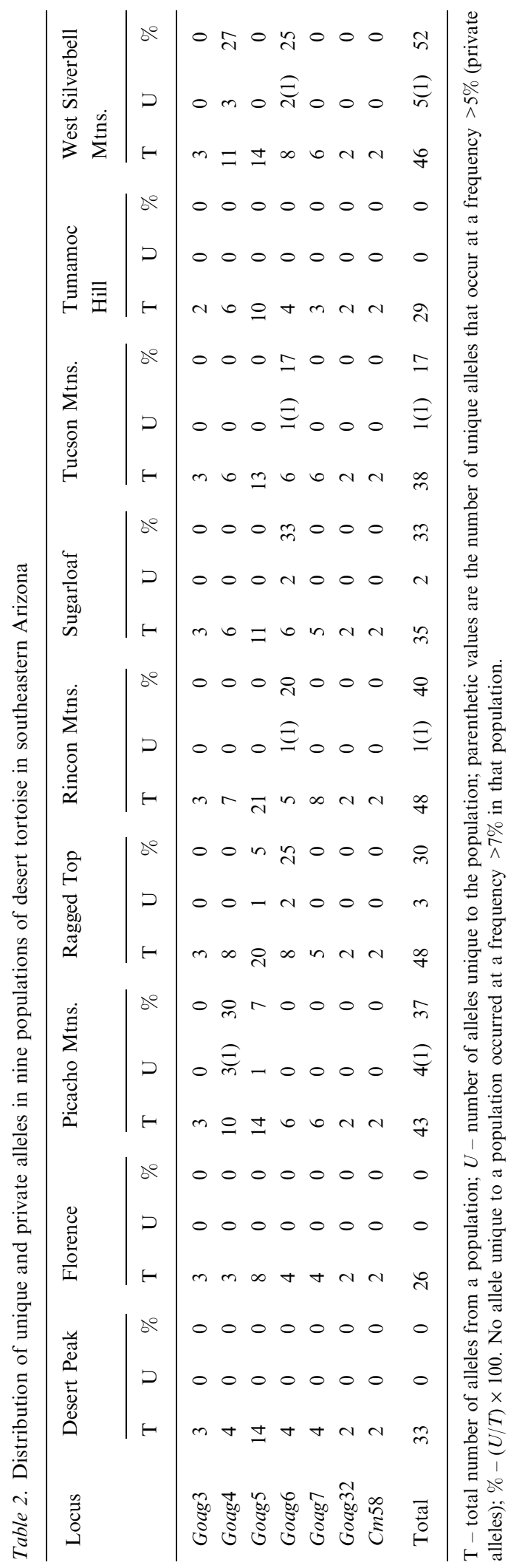

geographic distance of our sampled populations (Table 3). The correlation accounts for approximately $30 \%$ of the variation observed (Mantel test; $r^{2}=0.307, \quad P=0.030$ ). This correlation was maintained when pairwise $R_{\mathrm{ST}}$ was used as a measure of genetic distance $\left(r^{2}=0.222\right.$, $P=0.015)$.

\section{Within-population structure}

Since initiation of desert tortoise radiotelemetry studies in the Rincon Mountain at Saguaro National Park in 1996, no radiotelemetered tortoises have moved between the Rocking $\mathrm{K}$ and the Mother's Day Fire sites. However, results of the assignment test and the AMOVA indicate that gene flow occurs between the two sites despite geographic features (ridges and washes) that potentially separate them. The population assignment test only assigned three individuals to their correct site of origin with a LOD ratio exceeding two. We observed $76.9 \%(P<0.001)$ of genetic variation within the population, $20.7 \%$ $(P<0.001)$ among individuals within each site, and only $2.4 \%(P=0.056)$ between the two sites. The stepwise mutation model, did not detect any differentiation between the two sites $\left(R_{\mathrm{ST}}\right.$ was negative). There was no correlation between the genetic relationship among individuals (pairwise $\left.\Phi_{\mathrm{ST}}\right)$ and the geographic distance among their home ranges $\left(r^{2}=-0.005, P=0.289\right)$. The genetic structure within this single population suggests that genetic variation between individuals is not associated with behavior (home range) or habitat characteristics.

\section{Discussion}

\section{Phylogeography}

The phylogeographic pattern of shared, but also unique, microsatellite alleles among desert tortoise populations is indicative of intermediate gene flow in a species not subdivided by long-term zoogeographic barriers (Avise et al. 1987). The low frequency of private microsatellite alleles across populations and the significant correlation between genetic and geographic distance among populations is consistent with isolation-by-distance (IBD; 
Table 3. Population pairwise $\Phi_{\mathrm{ST}}$ values (below diagional) and geographic distances (above diagional; kilometers) among nine desert tortoise populations in southern Arizona

\begin{tabular}{lrlllllllrr}
\hline Population & $\#$ & DP & FL & SNP & PM & RT & SL & TH & TM & WSB \\
\hline Desert Peak (DP) & 12 & - & 66 & 72 & 16 & 27 & 123 & 48 & 31 & 41 \\
Florence (FL) & 8 & $0.091^{*}$ & - & 128 & 57 & 84 & 59 & 111 & 96 & 85 \\
Rincon Mountains (SNP) & 38 & 0.029 & $0.076^{*}$ & - & 88 & 81 & 186 & 30 & 48 & 99 \\
Picacho Mountains (PM) & 18 & 0.004 & $0.062^{*}$ & 0.001 & - & 27 & 112 & 63 & 44 & 33 \\
Ragged Top (RT) & 22 & 0.030 & $0.090^{*}$ & 0.004 & 0.000 & - & 138 & 52 & 33 & 18 \\
Sugarloaf (SL) & 27 & $0.056^{*}$ & $0.047^{*}$ & $0.061^{*}$ & $0.042^{*}$ & $0.041^{*}$ & - & 170 & 154 & 133 \\
Tumamoc Hill (TH) & 9 & 0.037 & $0.148^{*}$ & 0.027 & 0.008 & 0.018 & $0.097^{*}$ & - & 19 & 70 \\
Tucson Mountains (TM) & 18 & 0.015 & $0.107^{*}$ & $0.022^{*}$ & $0.026^{*}$ & $0.022^{*}$ & $0.076^{*}$ & $0.039^{*}$ & - & 51 \\
West Silver Bell Mountains & 18 & 0.026 & $0.102^{*}$ & 0.018 & 0.003 & 0.019 & $0.056^{*}$ & 0.027 & $0.035^{*}$ & - \\
(WSB) & & & & & & & & & & \\
\hline
\end{tabular}

* indicates significance level $P<0.05$.

Kimura and Weiss 1964). The IBD model for Sonoran desert tortoise populations is also evident in mitochondrial DNA sequence data from these same samples (Edwards 2003). The desert tortoise is perhaps the ideal organism for the IBD model; one that is distributed across the landscape in isolated patches and for which the difficulty of dispersal is a function of geography. Geographic distance between populations is the major limitation to panmixia. Within a continuously distributed population, however, topographic features do not appear to contribute significantly to withinpopulation genetic structure, as exemplified in our Rincon Mountain population.

\section{Gene flow}

Gene flow occurs, or occurred recently until the proliferation of anthropogenic barriers, among desert tortoise populations. The cohesion among populations detected by the AMOVA and the population assignment tests suggests that dispersal resulting in exchange of genetic material must have occurred in the past at a rate of at least one migrant per generation (OMPG) to alleviate differentiation resulting from mutation or genetic drift (Wright 1931). The results of the KS-test support that the variability shared among populations calculated using the AMOVA is representative of populations exhibiting similar distributions of allele frequencies. The distribution of low-frequency unique alleles detected across most populations and the lack of evidence for a recent expansion event support the hypothesis that this lack of differentiation is a result of gene flow and not common ancestry. Our estimates of migration using Slatkin's $\widehat{M}$ show a minimum of 2.9 migrants per generation between population pairs, but gene

Table 4. Slatkin's $\widehat{M}$ (absolute number of migrants exchanged per generation between populations) calculated among nine desert tortoise populations in southern Arizona

\begin{tabular}{|c|c|c|c|c|c|c|c|c|c|}
\hline Population & \# & DP & FL & SNP & $\mathrm{PM}$ & RT & $\mathrm{SL}$ & $\mathrm{TH}$ & $\mathrm{TM}$ \\
\hline Desert Peak (DP) & 12 & - & & & & & & & \\
\hline Florence (FL) & 8 & 5.0 & - & & & & & & \\
\hline Rincon Mountains (SNP) & 38 & 16.5 & 6.0 & - & & & & & \\
\hline Picacho Mountains (PM) & 18 & 129.7 & 7.6 & 393.3 & - & & & & \\
\hline Ragged Top (RT) & 22 & 16.3 & 5.0 & 113.2 & Inf. & - & & & \\
\hline Sugarloaf (SL) & 27 & 8.4 & 10.2 & 7.6 & 11.3 & 11.6 & - & & \\
\hline Tumamoc Hill (TH) & 9 & 12.9 & 2.9 & 18.0 & 61.9 & 28.0 & 4.6 & - & \\
\hline Tucson Mountains (TM) & 18 & 32.0 & 4.2 & 22.2 & 19.0 & 22.5 & 6.1 & 12.4 & - \\
\hline West Silver Bell Mountains & 18 & 18.9 & 4.4 & 28.1 & 151.8 & 26.2 & 8.4 & 17.9 & 13.7 \\
\hline
\end{tabular}

Estimates of $\widehat{M}$ for populations with pairwise $F_{\mathrm{ST}}$ values $\leq 0$ are considered to have an 'infinite' number of migrants. 
flow can be variable and unpredictable among populations due to a wide array of demographic and environmental factors (Daly and Patton 1990) and estimates of absolute numbers of migrants are not reliable using microsatellite markers (Balloux and Lugon-Moulin 2002). Genetic variance among populations $\left(\Phi_{\mathrm{ST}}\right)$ is only an indirect measure of gene flow and can be misleading when translated into dispersal rates (Whitlock and McCauley 1999). The conditional average frequency of private alleles used to estimate gene flow $(\mathrm{Nm}=5.5)$ also indicates gene flow above OMPG, but these measures should not be the only means used to draw inference of population structure. Therefore, we also rely on the natural history of tortoises to draw conclusions, including observation of a $32 \mathrm{~km}$ inter-population movement made by a radiotelemetered tortoise during the study (Edwards 2003). The most likely scenario for the desert tortoise is that gene flow occurs not at a regular rate, but with varying frequencies over time related to environmental fluctuations (Morafka 1994). For example, there may be increased potential for successful emigration in years of high rainfall. Similar measures of gene flow, based on microsatellite data, were found in populations of geometric tortoises (Psammobates geometricus) in the western Cape Province of South Africa $\left(F_{\mathrm{ST}}=0.031\right.$; Cunningham et al. 2002). This species shares a similar natural history with the desert tortoise in that the landscape contains physical barriers, such as mountains, that separate populations. In addition, the species is also long-lived and is faced with extreme habitat fragmentation due to human development.

We attribute the departure from HardyWeinberg equilibrium and associated positive inbreeding coefficient for some loci in our sample to population structure observed for Sonoran desert tortoises (Table 1). Among tortoise populations, geographic distance is an isolating force that affects the probability of individuals mating and thus violates the assumption of panmixia. The structured distribution of low-frequency and intermediate alleles across populations (Table 2) and significant correlation between genetic and geographic distance among populations we observed in our study make Hardy-Weinberg equilibrium an unreasonable expectation for this species. Deviations from Hardy-Weinberg equilibrium can also result from non-amplifying al- leles. However, we think the likelihood of this is small because all samples amplified for at least one allele, whereas we would expect some samples to not amplify at all (homozygotes) if null alleles were present in the population. Most (7 of 13) of the significant departures from Hardy-Weinberg equilibrium in our data set had $H_{\text {obs }}<50 \%$, as a result of relatively high numbers of homozygotes. The test of linkage disequilibrium assumes HardyWeinberg proportions, so linkage estimates may be incorrect due to the departure from HardyWeinberg equilibrium (Excoffier and Slatkin 1998). A structured population will exhibit allele associations as a consequence of non-random mating that are not a result of linkage within the genome. The possibility that some of our markers are linked may limit some of the conclusions that can be drawn from this analysis, but it did not impact our estimates of gene flow.

\section{Movement barriers}

The modern landscape of southern Arizona contains many recently constructed anthropogenic barriers that may obstruct movements of tortoises between populations and disturb patterns of gene flow. All of the populations we examined have at least a dirt road separating them (Figures 2 and 3). The only population pairs in our sample set that could conceivably still exchange individuals at a natural frequency are Desert Peak/Picacho Mountains and Ragged Top/West Silver Bells (Figure 1). All other connections between populations have human barriers that would seriously obstruct natural tortoise movements.

During the study, a radiotelemetered adult female tortoise made a long-distance movement of approximately $32 \mathrm{~km}$ from the Rincon Mountains to an adjacent mountain range (Santa Rita Mountains; Edwards 2003). This tortoise encountered several anthropogenic barriers that, without human intervention, would likely have been insurmountable. Researchers had to facilitate her movement across fence lines, railroad tracks, and an interstate highway. She was also captured several times and temporarily adopted by private citizens. The genetic data confirm that such longdistance movements result in the exchange of genetic material among adjacent populations. Because tortoises exhibit extremely long generation times with respect to the recent proliferation of 


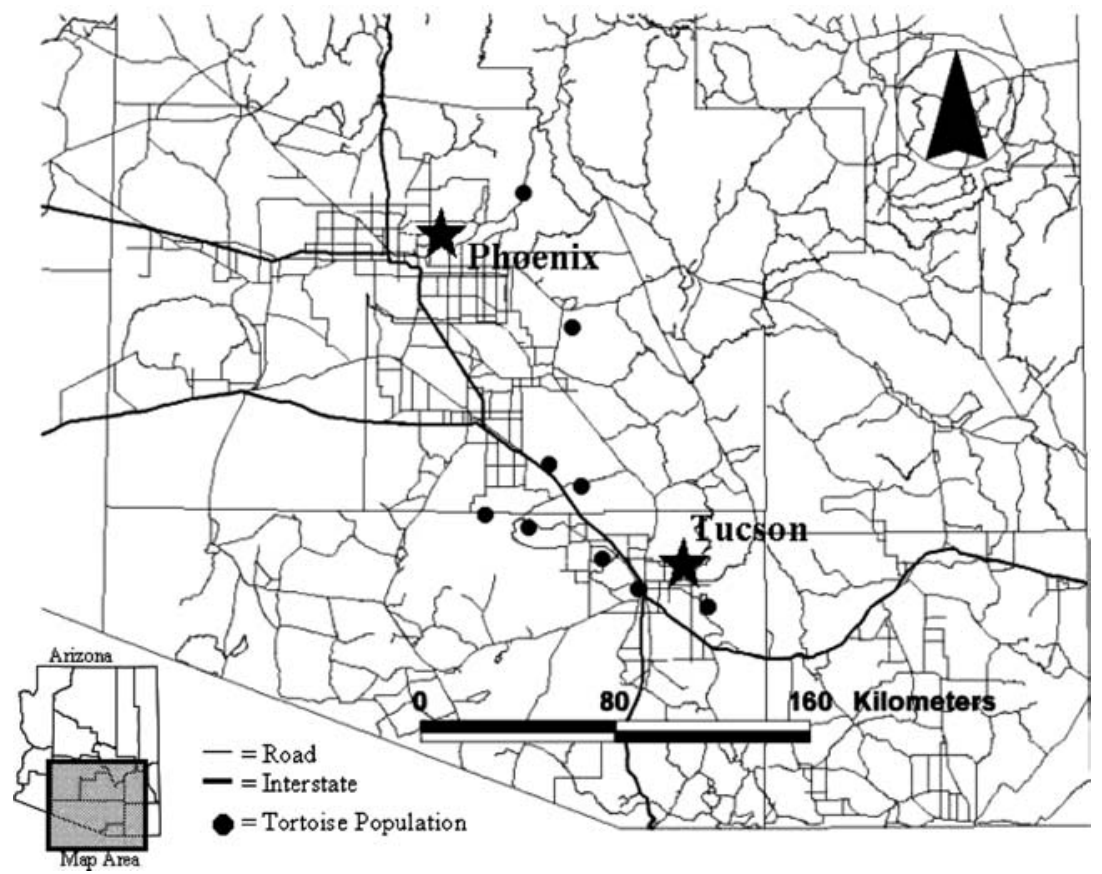

Figure 2. Distribution of interstates and major roads in southern Arizona that may obstruct tortoise movement between populations.

landscape barriers (Lovich and Bainbridge 1999), our estimates of gene flow predate anthropogenic habitat fragmentation and should not be taken as evidence that natural immigration/emigration still occurs. Documentation of this inter-population movement demonstrates that desert tortoises can

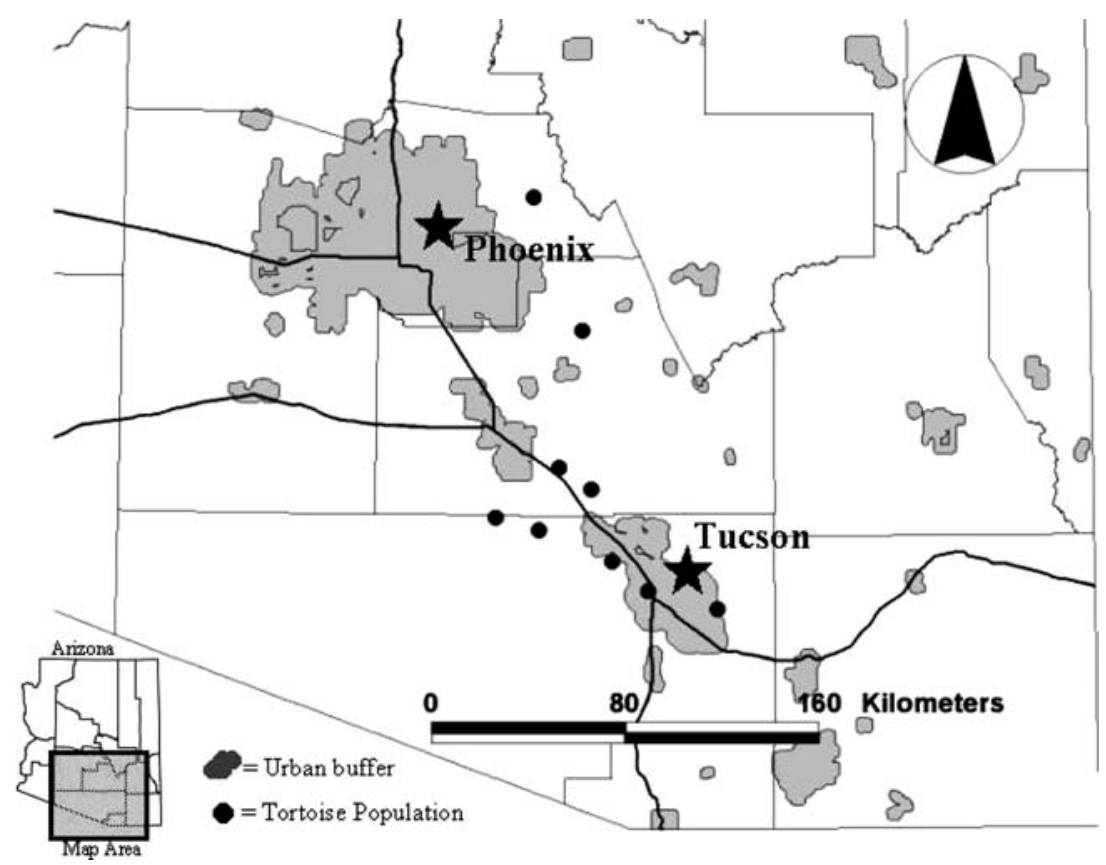

Figure 3. Distribution of urbanized areas in southern Arizona that may obstruct tortoise movement between populations. 
and sometimes are motivated to disperse great distances. However, the urban topography of the modern landscape makes such movements by tortoises virtually impossible without human assistance.

\section{Population viability}

Tortoise populations confined to foothill habitats in southern Arizona are likely to be small. Three separate population viability analyses (PVAs) conducted on the Mojave population of the desert tortoise recommend that a minimum of 50,000 individuals is necessary for a $50 \%$ chance of persistence for 500 years (Doak et al. 1994; USFWS 1994). Estimated densities of tortoises in optimal areas in southern Arizona range from 23 to 56 adults $/ \mathrm{km}^{2}$ (Averill-Murray et al. 2002). A rough extrapolation suggests that most mountain ranges likely contain far less than 20,000 adult tortoises (with some only having several hundred). Thus, population levels in any given mountain range are far below that recommended by the PVAs generated for Mojave desert tortoises. We did not find evidence using these microsatellite loci indicative of a recent $(<1000$ generations) genetic bottleneck that would otherwise explain a small population size. However, our small sample size and number of alleles may limit our ability to detect recent bottlenecks. Edwards (2003) estimated the time to most recent common ancestor (TMRCA) based on mitochondrial DNA from these same samples to be $>170 \mathrm{kya}$, which is consistent with there not being recent bottlenecks in the study area. The inference that tortoises maintain long-term, small effective population size is also supported by a low degree of nucleotide diversity and polymorphism among mitochondrial DNA sequences (Edwards 2003). Because effective population sizes of Sonoran desert tortoises are small, dispersal events probably play an important role in the long-term maintenance of these populations. Life history traits of the desert tortoise, a long-lived species with delayed sexual maturity, suggest that there are severe constraints on the ability of populations to respond to chronic disturbances (Congdon et al. 1993). Demographic modeling for tortoises indicates that adult females are the most crucial life stage for population longevity, such that even a small increase in their mortality rate could result in a population crash
(Doak et al. 1994). It is unlikely that a closed population of desert tortoises experiencing a dramatic reduction in adult survivorship would be able to offset that loss through compensatory increase in reproductive output. The high level of past gene flow among populations suggests that if a population were to experience a catastrophic decline as a result of drought or other stochastic event, its recovery may rely heavily on the immigration of new individuals from adjacent mountain ranges for recovery.

\section{Management and conservation implications}

We demonstrate that tortoises in our study area historically dispersed between mountain ranges and that inter-population movements may be critical to the persistence of small tortoise populations. Maintaining landscape connectivity should be the first objective in assuring the persistence of these populations. However, because many historic dispersal routes are no longer available to desert tortoises as a result of anthropogenic landscape change, informed management strategies need to be in place to facilitate the longterm persistence of Sonoran desert tortoise populations. Many tortoise populations are becoming islands surrounded by human development. Encroachment of human development makes tortoise populations vulnerable to multiple threats, such as road mortality, illegal take, and exposure to disease from escaped or released domestic tortoises (AIDTT 2000).

An excellent example of a desert tortoise population imperiled by landscape change is the population at Tumamoc Hill (Figure 1) within the city limits of Tucson. Tumamoc Hill hosts a very small $(<30)$, but currently persisting population of tortoises. This population is essentially an island completely surrounded by urban development. The effects are apparent in the tortoise population; the population is small and many of the individuals we found exhibited shell trauma from domestic or feral dog attacks (Edwards 2003). The proximity of this site to people's homes also makes the tortoise population vulnerable to escaped or released domestic tortoises that are a potential source of disease to wild populations (AIDTT 1996). The probability of this population experiencing a decline from human-related activities seems inevitable. Since there is no dependable way 
for new tortoises to naturally immigrate into the population due to the proliferation of heavily traveled roads surrounding it, the population will likely be extirpated. Because of the long lifespan of desert tortoises, a local extinction could take decades. Management strategies for an imperiled population like that on Tumamoc Hill should address what the barriers are to tortoise movement and the possibility of translocating new individuals into the population.

The genetic data suggest that gene flow among populations is part of the evolutionary history of the desert tortoise and therefore inter-population movements may be critical to the long-term viability of populations. Assessing what constitutes a barrier to movement for tortoises is necessary for maintaining connectivity between populations. While a roadway may not be a barrier to a large ungulate, it may be impenetrable to a tortoise. Tortoises are able to cross some barriers and have been shown to use culverts (Ruby et al. 1994). Fencing or concrete barriers along highways may also help guide tortoises toward appropriate crossing areas and prevent road mortality. Placement of culverts and corridors needs to specifically accommodate tortoises, as corridors designed for general wildlife use may not be effective (Barrett et al. 1990).

Microsatellite data can be used to design effective translocation strategies for wildlife by providing information on the rate of gene flow, the level of divergence between populations, genetic variability of populations, and the number of individuals for translocation (Maudet et al. 2002). Translocation of tortoises from nearest-neighbor populations should be evaluated as a potential management strategy to recover or maintain small populations isolated by anthropogenic barriers. Tortoises generally exhibit strong site tenacity (Barrett et al. 1990, Bailey 1992), and translocation studies of reptiles indicate that they generally fare poorly in unfamiliar areas (Barrett et al. 1990; Dodd and Seigel 1991; Reinert and Rupert 1999). However, preliminary studies in the Mojave Desert indicate that translocation may be an effective strategy for supplementing depauperate populations of desert tortoises (Tracy et al. 2000). Currently in Arizona, tortoises are sometimes relocated short distances during construction projects (AIDTT 1996). Before inter-population translocation of tortoises is implemented as a conservation strategy in the Sonoran Desert, effects of translocation on survivorship of relocated individuals and the populations into which they are introduced need to be evaluated and the potential for disease transmission from one population to another needs to be assessed (Dodd and Seigel 1991; Jacobson 1993; Cunningham 1996; Seigel and Dodd 2002). In addition, translocation will not likely be a sustainable strategy unless threats are also identified and alleviated. While it may be tempting to apply the OMPG rule to isolated tortoise populations not declining, different schedules of supplementation may be appropriate depending on environmental and demographic conditions specific to each population (Mills and Allendorf 1996). Management strategies compatible with the evolutionary history of gene flow among disjunct populations will help ensure the long-term persistence of Sonoran desert tortoise populations.

\section{Acknowledgements}

This project was accomplished through the generosity of many individuals and organizations, including over 75 volunteers that provided field assistance and technical support. In particular, this study would not have been possible without the dedication of E. Stitt and M. Kaplan. R. AverillMurray, R. Repp, J. Jarchow, J. Johnson, S. Barrett, T. Christopher, P. Woodman all lent invaluable expertise. M. Hammer and the knowledgeable staff at the Genomic Analysis and Technology Core facilitated molecular procedures and analysis. We are grateful to Saguaro National Park for supporting this study, particularly $\mathrm{N}$. Kline and M. Weesner. T. Esque of the US Geological Survey generously shared data from the Mother's Day Fire site. We thank the Tucson Herpetological Society for their continued support for research and conservation of regional herpetofauna.

This project was funded primarily by the Arizona Game and Fish Department Heritage Fund (IIPAM Project No. I20012). The Southwestern Parks and Monuments Association and the Desert Southwest Cooperative Ecosystem Study Unit provided additional financial support. Samples were collected under scientific research permits from the Arizona Game and Fish Department and 
Saguaro National Park. Tortoise handling protocols were approved by the University of Arizona (IACUC 00-084).

\section{References}

Arizona Game and Fish Department (AGFD) (1996) Wildlife of special concern in Arizona (public review draft). Arizona Game and Fish Department, Phoenix, USA.

Arizona Interagency Desert Tortoise Team (AIDTT) (1996) Management plan for the Sonoran Desert population of the desert tortoise in Arizona. Arizona Interagency Desert Tortoise Team and Arizona Game and Fish Department, Phoenix, USA.

Arizona Interagency Desert Tortoise Team (AIDTT) (2000) In: Status of the Sonoran Population of the Desert Tortoise in Arizona: An Update. (ed. Averill-Murray RC), Arizona Interagency Desert Tortoise Team and Arizona Game and Fish Department, Phoenix, USA.

Averill-Murray RC (2000) Survey protocol for Sonoran Desert tortoise monitoring plots: Reviewed and revised. Arizona Interagency Desert Tortoise Team and Arizona Game and Fish Department, Phoenix, USA.

Averill-Murray RC, Klug CM (2000) Monitoring and ecology of Sonoran Desert tortoises in Arizona. Nongame and Endangered Wildlife Program Technical Report 161. Arizona Game and Fish Department, Phoenix, USA.

Averill-Murray RC, Woodman AP, Howland JM (2002) Population ecology of the Sonoran desert tortoise in Arizona. In: The Sonoran Desert Tortoise: Natural History, Biology, and Conservation (ed. Van Devender TR), pp. 109-134. University of Arizona Press, Tucson, USA.

Avise JC, Arnold J, Ball RM, Bermingham E, Lamb T, Neigel JE, Reeb CA, Saunders NC (1987) Interspecific phylogeography: The mitochondrial DNA bridge between population genetics and systematics. Ann. Rev. Ecol. Syst., 18, 489-522.

Bailey SJ (1992) Hibernacula Use and Home Range of the Desert Tortoise (Gopherus agassizii) in the San Pedro Valley, Arizona. M.S. thesis, University of Arizona, Tucson, USA.

Balloux F, Lugon-Moulin N (2002) The estimation of population differentiation with microsatellite markers. Mol. Ecol., 11, 155-165.

Banks MA, Eichert W (2000) WHICHRUN (version 3.2): A computer program for population assignment of individuals based on multilocus genotype data. J. Hered., 91, 87-89.

Barrett SL, Humphrey JA, Harper SD (1990) Desert tortoise reintroduction and mitigation assessment study: Final report. Bureau of Reclamation, Arizona Projects Office, Central Arizona Project, Phoenix, USA.

Barton NH, Slatkin M (1986) A quasi-equilibrium theory of the distribution of rare alleles in a subdivided population. Heredity, 56, 409-415.

Chakravarti IM, Laha RG, Roy J (1967) Handbook of Methods of Applied Statistics. John Wiley and Sons, New York, USA.

Congdon CD, Dunham AE, Van Loben Sels RC (1993) Delayed sexual maturity and demographics of Blanding's turtles (Emydoidea blandingii): Implications for conservation and management of long-lived organisms. Conserv. Biol., 7(4), 826-833

Cornuet JM, Luikart G (1996) Description and power analysis of two tests for detecting recent population bottlenecks from allele frequency data. Genetics, 144, 2001-2014.
Cunningham AA (1996) Disease risks of wildlife translocations. Conserv. Biol., 10(2), 349-353.

Cunningham J, Baard EHW, Harley EH, O'Ryan C (2002) Investigation of genetic diversity in fragmented geometric tortoise (Psammobates geometricus) populations. Conserv. Genet., 3, 215-223.

Daly JC, Patton JL (1990) Dispersal, gene flow, and allelic diversity between local populations of Thomomys bottae pocket gophers in the coastal ranges of California. Evolution, 44(5), 1283-1294.

Doak D, Kareiva P, Klepetka B (1994) Modeling population viability for the desert tortoise in the Western Mojave Desert. Ecol. Appl., 4(3), 446-460.

Dodd CK, Seigel RA (1991) Relocation, repatriation and translocation of amphibians and reptiles: Are they conservation strategies that work? Herpetologica, 47, 336-350.

Edwards T (2003) Desert Tortoise Conservation Genetics. Unpublished M.S. thesis, University of Arizona, Tucson, USA.

Edwards T, Goldberg CS, Kaplan ME, Schwalbe CR, Swann DE (2003) PCR primers for microsatellite loci in the desert tortoise (Gopherus agassizii, Testudinidae). Mol. Ecol. Notes, 3(4), 589-591.

Esque TC, Nijuis MJ, Haines DF, Clark JW, Swantek PJ, Schwalbe CR (1998) Effects of fire on desert tortoises at Saguaro National Park. In: Expanded Abstracts of Second Conference on Research and Resource Management in Southern Arizona National Park Areas (eds. Benson L, Gebow G), pp. 36-37. National Park Service, Phoenix, Arizona, USA.

Excoffier L, Slatkin M (1998) Incorporating genotypes of relatives into a test of linkage disequilibrium. Am. J. Human Genet., 62(1), 171-180.

FitzSimmons NN (1998) Single paternity of clutches and sperm storage in the promiscuous green turtle (Chelonia mydas). Mol. Ecol., 7, 575-584.

FitzSimmons NN, Moritz C, Moore SS (1995) Conservation and dynamics of microsatellite loci over 300 million years of marine turtle evolution. Mol. Biol. Evol., 12(3), 432-440.

Garza JC, Williamson EG (2001) Detection of reduction in population size using data from microsatellite loci. Mol. Ecol., 10, 305-318.

Goldberg CS, Kaplan ME, Schwalbe CR (2003) From the frog's mouth: Buccal swabs for collection of DNA from amphibians. Herpetol. Rev., 34(3), 220-221.

Goudet J (1995) Fstat version 1.2: A computer program to calculate $F$ statistics. J. Hered., 86(6), 485-486.

Goudet J, Raymond M, De Meeüs T, Rousset F (1996) Testing differentiation in diploid populations. Genetics 144, 19331940

Guo SW, Thompson EA (1992) Performing the exact test of Hardy-Weinberg proportions for multiple alleles. Biometrics, 48, 361-372.

Hamilton MB, Pincous EL, Di Fiore A, Fleischer RC (1999) Universal linker and ligation procedures for construction of genomic DNA libraries enriched for microsatellites. BioTechniques, 27, 500-507.

Hooge PN, Eichenlaub B (1997) Animal movement extension to Arcview. ver. 1.1. Alaska Science Center - Biological Science Office, U.S. Geological Survey, Anchorage, USA.

Jacobson ER (1993) Implications of infectious diseases for captive propagation and introduction programs of threatened/endangered reptiles. J. Zoo Wildlife Med., 24(3), 245255 . 
Kimura M, Weiss GH (1964) The stepping stone model of population structure and the decrease of genetic correlation with distance. Genetics, 49, 561-576.

King MB, Duval D (1990) Prairie rattlesnake seasonal migrations: Episodes of movement, vernal foraging and sex differences. Anim. Behav., 39, 924-935.

Lovich JE, Bainbridge D (1999) Anthropogenic degradation of the Southern California desert ecosystem and prospects for natural recovery and restoration. Environ. Manage., 24(3), 309-326.

Maudet C, Miller C, Bassano B, Breitenmoser-Würsten C, Gauthier D, Obexer-Ruff G, Michallet J, Taberlet, Luikart P (2002) Microsatellite DNA and recent statistical methods in wildlife conservation management: Applications in Alpine ibex [Capra ibex (ibex)]. Mol. Ecol., 11(3), 421-436.

Mills LS, Allendorf FW (1996) The one-migrant-per-generation rule in conservation and management. Conserv. Biol., 10(6), 1509-1518.

Morafka DJ (1994) Neonates: Missing links in the life histories of North American tortoises. In: Biology of North American Tortoises (eds. Bury RB, Germano DJ), pp. 161-173. Fish and Wildlife Research no. 13. U.S. Department of the Interior National Biological Survey, Washington, DC, USA.

Piry S, Luikart G, Cornuet JM (1999) BOTTLENECK: A computer program for detecting recent reductions in effective population size using allele frequency data. J. Hered., 90, 502-503.

Raymond M, Rousset F (1995) GENEPOP (version 1.2): Population genetics software for exact tests and ecumenicism. J. Hered., 86, 248-249.

Reinert HK, Rupert RR (1999) Impacts of translocation on behavior and survival of timber rattlesnakes. J. Herpetol., 33, 45-61.

Ruby DE, Spotila JR, Martin SK, Kemp SJ (1994) Behavioral responses to barriers by desert tortoises: Implications for wildlife management. Herpetol. Monogr., 8, 144-160.

Schneider S, Roessli D, Excoffier L (2000) Arlequin version 2.000: A Software Program for Population Genetics Data Analysis. Genetics and Biometry Laboratory, Geneva, Switzerland.
Seigel RA, Dodd Jr CK (2002) Translocations of amphibians: proven management method or experimental technique. Conserv. Biol., 16(2), 552-554.

Sites Jr JW, FitzSimmons NN, DA Silva Jr NJ, Cantarelli VH (1999) Conservation genetics of the giant Amazon turtle (Podocnemis expansa; Pelomedusidae) - inferences from two classes of molecular markers. Chelonian Conserv. Biol., 3(3), 454- 463.

Slatkin M (1991) Inbreeding coefficients and coalescence times. Genet. Res., 58(2), 167-175.

Slatkin M (1995) A measure of population subdivision based on microsatellite allele frequencies. Genetics, 139, 457-462.

Slatkin M, Excoffier L (1996) Testing for linkage disequilibrium in genotypic data using the EM algorithm. Heredity, 76, 377-383.

Slatkin M, Maddison WP (1990) Detecting isolation by distance using phylogenies of genes. Genetics, 126(1), 249-260.

Tracy CR, Nussear KE, Wilson DS, Field K, Medica PA, Marlow RM, Saethre MB, Corn PS, Simandle ET (2000) Translocation as a tool for conservation of the desert tortoise: Is translocation a reasonable strategy for desert tortoises displaced by urban expansion? The Desert Tortoise Council 26th Annual Meeting and Symposium Abstracts. Las Vegas, Nevada, USA.

Turner RM, Brown DE (1982) Sonoran desertscrub. In: Biotic Communities of the American Southwest - United States and Mexico (ed. Brown DE), pp. 180-221. Desert Plants, 4(1-4), $1-342$.

U.S. Fish and Wildlife Service (1990) Endangered and threatened wildlife and plants: determination of threatened status for the Mojave population of the desert tortoise. Fed. Reg., 55, 12178-12191.

U.S. Fish and Wildlife Service (1994) Desert Tortoise (Mojave Population) Recovery Plan. U.S. Fish and Wildlife Service, Portland, Oregon, USA.

Weir BS, Cockerham CC (1984) Estimating $F$-statistics for the analysis of population structure. Evolution, 38, 1358-1370.

Whitlock MC, McCauley DE (1999) Indirect measures of gene flow and migration: $F_{\mathrm{ST}} \neq 1 /(4 \mathrm{Nm}+1)$. Heredity, 82, 117 125.

Wright S (1931) Evolution in Mendelian populations. Genetics, 16, 97-159. 